\title{
how to avoid the seven deadly sins of academic writing
}

\author{
gerald schneider
}

Department of Politics and Public Administration, University of Konstanz, Box 86, Konstanz 78457, Germany

\begin{abstract}
Doing justice to the often-ridiculed medieval catechism, this article identifies individual-level barriers to an efficient publication strategy in political science and beyond. I argue that becoming a successful and innovative academic writer needs a clear understanding of the (unholy) trinity between authors, reviewers and editors. Based on the analysis of the publication market, I introduce the 'seven deadly sins of academic writing' and conclude with uncle G.'s official list of publication virtues that promise increasing research productivity.
\end{abstract}

Keywords research productivity; innovation; academic catechism; publication virtues

$\mathrm{O}$ ccupying a prominent place in the history of mankind, at least since Dante's Divina Commedia, the seven deadly sins have been among us cognoscenti since the fourth century $A D$. In the Middle Ages, breaking these moral rules merited nothing less than the damnation of the offenders. Alas, a plethora of fashionable concepts - among them, not the least, critical thinking - has rendered this threat largely ineffective. In what is alltoo-often described as the modern era, so-called artists praise individuals for indulging a lush life that they wrongly associate with the seven deadly sins. An especially severe culprit has been the 'pop culture' that has vulgarised Western societies over the past 50 years. Beatle George Harrison is far from alone in his frivolous claim that 'Seven deadly sins/That's when the fun begins'. The Lucifer in Mick Jagger and Keith Richard's 'Sympathy for the Devil' (sic!) aptly describes the relativism which tears at the fabric of our societies. Begging for 'some restraint', the Devil dares to state: 'Just as every cop is a criminal and all the sinners saints ...'1

This article will not engage a hopeless struggle with the hedonism, cynicism and nihilism that predominate in our culture. Our goal is much more modest: we aim to remind the academic 


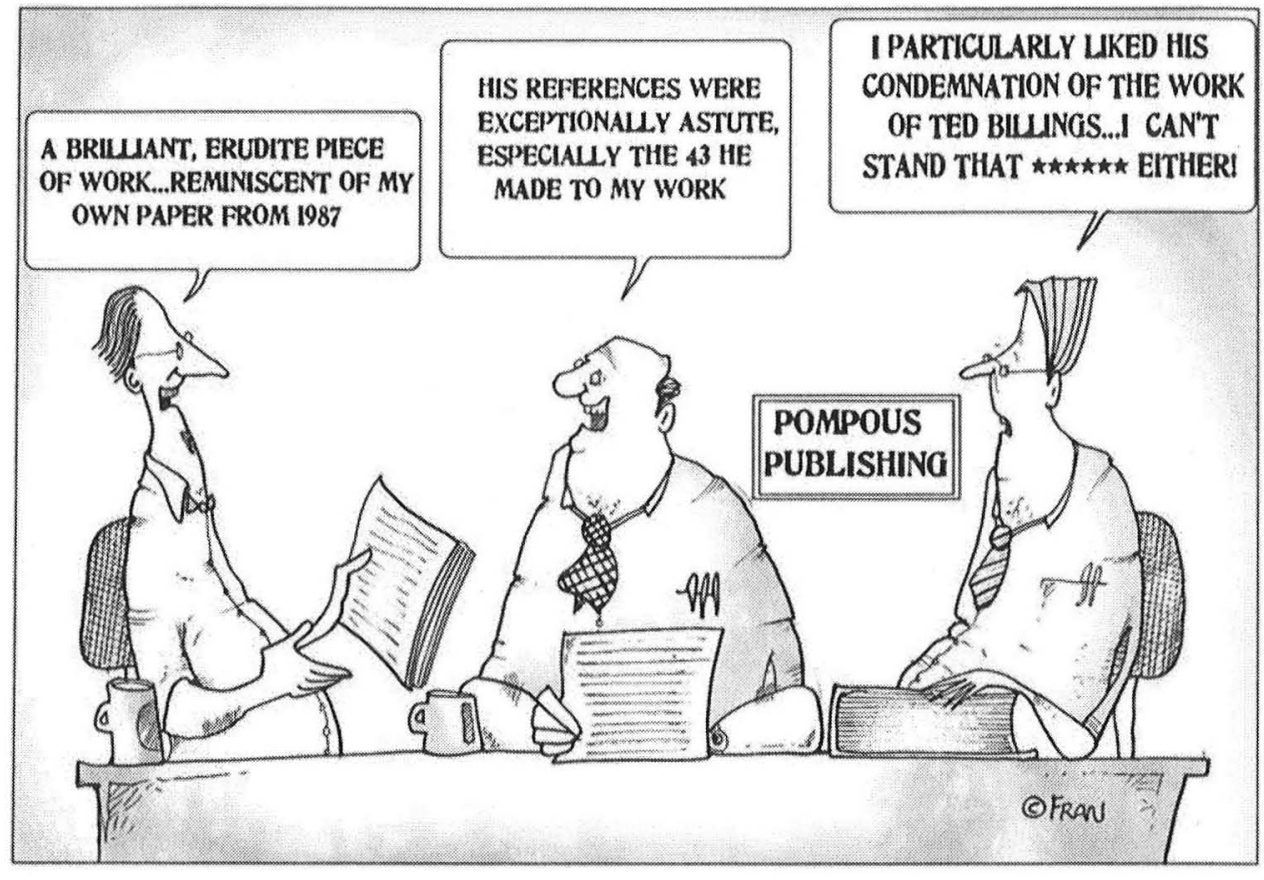

(C)fran@francartoons.com

community that the scientific equivalent to the capital sins has existed for a very long time in our intellectual quarters. In particular, the seven deadly sins of academic writing are: (1) silentium (perfectionism); (2) pigritia (idleness); (3) civilitas (civility); (4) invidia (enviousness); (5) procrastinatio (procrastination); (6) inhabilitas (clumsiness); and (7) logorrhoe (verbal diarrhoea).

As is well known, European social science is under attack from two directions. First (and most evidently), our deep insights attract nothing but disdain from politicians and civil servants (Schneider, 2007). But European social science is also a victim of the immorality that has beset our discipline; an immorality that is frequently allied with a blatant disrespect for the virtues of successful publishing. We will enumerate on the academic capital sins after an exposition on the social context of academic writing.

\section{THE AUTHOR-EDITOR- REVIEWER TRINITY OF ACADEMIC WRITING}

Cultural history is full of tragic love triangles in which a heroine (or, less frequently, a hero) cannot make the fateful decision between two attractions typically a beautiful dumbass and an ugly wisecrack. As far as research production is concerned, academic life imitates art. What we call the unholy trinity is the triangular relationship between aspiring authors, grumpy editors and cynical reviewers; a relationship as full of misunderstanding, hatred and self-inflated egos as is the typical fictitious ménage à trois.

In the less titillating academic equivalent to love triangles, publication is all that counts. Authors are only promoted if they publish, journals only exist if editors know how to fill them, and reviewers would have nothing to complain about if 
there were not 'unsalvageable', 'crappy', 'undistinguished', 'minor' or 'completely useless' manuscripts expressing 'idiocy', 'banality', 'mediocrity' or just 'utter emptiness'.

We contend that it is this trinity of authors, editors and reviewers that collectively uphold the virtues of academic writing. After reading this academic catechism, it is our hope that even the strongest doubters will concede that we would all be capital sinners without the pressures imposed by the peerreview system. In other words, we would all burn in academic hell if editors and reviewers did not save us from our own infatuation with the capital sins of scientific writing. Obviously, some of our peers misuse their power: like dark knights they try to prevent the publication of our important (and sometimes not so important) insights. But there are many publication outlets (more than 110 political science journals are currently indexed in the SSCI!), so that authors need not depend completely on a single editor or journal. Authors can escape criticism from the most stubborn of their peerreviewing colleagues. While there are those who would believe that they have landed in purgatory because of sinister colleagues who have prevented them from publishing their path-breaking insights; it is more likely that these colleagues have not taken the academic catechism seriously enough.

We recognize that publication markets are neither fair nor perfect. The Mathew effect provides the best evidence that markets are both hierarchical and undemocratic, but ultimately also meritocratic (Merton, 1968). According to this empirical law, those who publish continue to publish more, and those who don't publish will remain largely silent. ${ }^{2}$ To put it differently, for scientific authors, the Matthew effect implies that you cannot manipulate the market in the long run, regardless of how desperately you try.
The most productive scholars - not those with the best networks, the fattest grants, or those who are the most imaginative committee backstabbers and/or greatest research managers - will therefore be the ones who can escape academic purgatory.

Still, there are at least two ways in which authors can pump up their scientific visibility and impact over the short run. First, they can produce papers, which rely on tautologies for which they find after excessive data mining; it should be added - marginal empirical support. This hapless cooking of 'significant' results is the supply side of what we know as 'publication bias'. ${ }^{3}$ This notion stands for the willingness of editors to publish articles with findings at the brink of statistical non-significance, while those very same editors loathe to accept pieces that lack one-, two- or three-starred 'findings' at conventional levels of significance.

A second way in which opportunistic authors can successfully manipulate the publication market is through self-citations. For example, Fowler and Aksnes (2007), in an evaluation of Norwegian academic publications, show that referring to one's own previous publications ultimately pays off (regardless of how farfetched such a reference might actually be). According to their estimations, one additional self-citation brings in an average harvest of three citations by other researchers after 5 years. In return, this strong relationship suggests that authors have an incentive to behave strategically and to cite those who have a higher publication potential. ${ }^{4}$ Given these incentives, it is no surprise that academia makes for strange bedfellows. There are even those authors who have calculated the presence of seasonal shifts in acceptance ratios (Shalvi et al, 2010), so as to optimize publication success (until competitors have caught up with the trend).

Editors, of course, are seldom pure do-gooders, as they wish to portray 
themselves; there is, no doubt, a special VIP section in academic purgatory reserved for editors. However, their attempts to encourage citations to their own journals only partly pay off. According to Starbuck (2005), excessive selfcitations are an attribute of low-ranking journals, rather than the top outlets in a field. Rather, the more common editorial $\sin$ is the editor's contribution to the proliferation of 'normal science': the increase in articles that make only a marginal contribution to our cumulative knowledge. An additional editorial sin can be found in the fostering of mistaken collective beliefs, when journals require that a unanimous panel of referees must support the publication of a piece. Papers that flatter the 'conventional wisdom' easily jump over this threshold, especially if the author was clever and strategic enough to cite all the self-appointed veto players in the first place. A revolutionary article that questions academic groupthink faces a much harder challenge, given the consensus norm. It is not surprising, then, that some of the most innovative papers by future Nobel Prize winners were shelved for years before they were published in relatively lowranking journals (Gans and Shepherd, 1994). The persistence of these colleagues provides evidence that internationalization of the virtues of academic writing ultimately pays off.

Some reviewers contribute to the problems by insisting that some nitty-gritty technical detail needs to be addressed before an article can seriously be considered. Ellison (2002a, b) suggests that this tendency is responsible for a lengthening of the review process in our sister discipline of economics. In political science incredibly, and by contrast - the time from submission to first decision has diminished at many journals. This is obviously a positive development, but it begs the question of its cause. Three possible explanations avail themselves:

\section{'... there is, no doubt, a special VIP section in academic purgatory reserved for editors'.}

that we, as reviewers, have become more superficial, that reviewers have become more committed to the public good; or that the papers under review have become shallower. We believe that a mixture of all three explanations is at work. After all, the reviewers who we are, and those whom we face, are more or less the same. They range from the competition-obsessed junior faculty member who opposes everything, including his own work, to the softened senior colleague who promiscuously accepts everything out of her belief in humankind (This colleague is a sinner like me, save him from the purgatory!).

The reviewing process that binds together authors, editors and reviewers in often changing roles is an unsavoury business, not unlike sausage making. But the end result remains palatable and there are no known alternative for delivering better overall results in the sciences. Indeed, Cherkashin et al (2009), in an evaluation of leading economics journals, shows that journals do not as frequently accept a paper that will have no impact at all, while journals reject those pieces that turn out to be influential at another journal.

\section{THE SEVEN DEADLY SINS ...}

Understanding how the publication market works is one strategy for becoming a successful author. Just as important is the need to avoid the seven deadly sins of academic writing. These sins can limit your initial innovative and productive potential.

Perfectionism is the most excusable of all deadly sins. We all know of colleagues 
and students who find it difficult to submit their work to journals. After all, who among us has not found herself or himself concerned about some small detail that might have been overlooked, or worried over some potential competitor who might have had the very same idea and could formulate it in a less embarrassing way? The only remedy against this sin is to increase one's self-confidence. Hence, to avoid the punishment for perfectionists in academic purgatory (sitting on your eternally burning unpublished papers), you need to become arrogant and internalize the three steps of any successful research project: First, you need to identify the social or political problem; second, you need to take the current explanation for this phenomenon into account, and, third, you must demonstrate credibly that what others have to say is nothing more than crap.

Idleness is a deadly sin that takes many forms. Of these, one of the more understandable is the insistence on writing about slightly esoteric topics. As an example to avoid, consider the relationships of poet Johann Wolfgang von Goethe towards the Swiss cotton industry (Bertheau, 1888) that were, in any account, mainly of an erotic nature. On the other hand, authors are required to produce an original idea if they really want to devote the remainder of their academic life to such a subject. A definitively damnable expression of idleness is the lack of ambition; this manifests itself in: (1) the avoidance of an original thought, at any cost; (2) the submitting of a marginal contribution to the Journal of Guaranteed Acceptance; ${ }^{5}$ or (3) a third-class burial of the very same piece in a volume edited by yourself or your former advisor. The daily punishments in purgatory for idle sinners are two in number: an obligation to grade (every day!) a thesis on the foreign policies of Liechtenstein and Andorra from 1973 to 1974 , or an evaluation of the discourse

\section{'Just as important is the need to avoid the seven deadly sins of academic writing'}

quality of eminent political scientists, having downed a sixth glass of burgundy.

Civility: One of the many quotes attributed to Kingsley Amis, author of the campus novel Lucky Jim, is the blunt wisdom that '[I]f you can't annoy somebody, there's little point in writing'. Indeed, there is ample evidence that those who want to please everyone fail miserably in making any point at all. Hence, to avoid academic purgatory, you need to take sides and to avoid contributing to the public bad of collective boredom (which results from an abundance of tactfulness at academic conferences or in scientific journals). In this call for a measure of incivility, we are not suggesting that you should refer to the proponents of errant beliefs as 'idiots' or 'a bunch of monkeys'. It is entirely sufficient to become only a bit vitriolic and to state that their ideas are deeply flawed, stupid and dangerous. Nevertheless, sinners need be aware of the requirement to contribute a 100,000 word essay, every second week, in academic purgatory. Using an informed triangulation of storytelling (i.e. process tracing), uncritical thinking and hermeneutical cross-tabulations, they need therein to show in an uncontroversial manner that: (1) autocracies of the Gaddafian mould are really more peaceful than democracies; or (2) how the ontology of the median voter diminishes the social capital of postmodernity.

Enviousness: Heretical economists have shown that envy (the car of my neighbour is larger than my own) hurts social productivity and hampers economic 
growth (e.g. Rabin, 1998). It should go without saying that enviousness exists across the academy. It manifests itself among tenured academics that embellish their CVs with lists of planned papers (intended to be submitted to ...) or that endeavour to maximize the size of their own office, the number of underlings under their command, or their frequency of appearances in the local newspaper. For the untenured among us, we find functional equivalents in the desire to maximize the number of minibar drinks on any given field trip, the tendency to note conference appearances without paper presentations, and the need for tattoos that praise non-conventional sources of intellectual inspiration (such as grandma's poodle) or that visualize Lucifer with pictures of the thesis supervisor. There is a double punishment for the envious sinners in academic hell: first, these sinners are required to read all the articles of their direct competitors themselves (without having the possibility of delegating this task to their research assistants) and, second, they need to finish all the papers that they have planned, but ultimately failed to deliver (as being envious stole so much time).

Procrastination: Cultural pessimists, like the author of these lines, maintain that individuals in modern societies simply possess too many options. Too many temptations turn our attention away from the higher goods to which we are supposed to contribute: namely, truth and the stability of the social order. In modern times, an abundance of distractions lurks in the dark, they seem to force us to procrastinate and to postpone important work. Social networking is one guaranteed way through which an aspiring academic can fall victim to this sin. The best indicator for measuring this risk is a count of the number of times a researcher hits the 'I like it' button on Facebook. ${ }^{6}$ For

\section{'Good writing skills and abstaining from modern media are not sufficient conditions for academic success ...'}

the more old-fashioned among us, an equivalent measure can be found in the frequency of requests for more 'political relevance' in our discipline, or by the time spent in the public transportation and parking committee of one's university. According to the academic catechism, procrastinators will be forced to update their Facebook status in hell every half hour, without having the possibility of resorting to repetitive prose, like 'still burning'.

Clumsiness or a distinct lack of writing skills, is an increasingly common sin committed by our colleagues. Obviously, the number of illiterates in our business is small, but the number of semi-literates is growing quickly due to the corrupting influence of Twitter, Facebook and mobile phones. These tools of 'modernity' force us to write in an asthmatic kind of language devoid of verbs and filled with randomized punctuation: ' $3 \mathrm{am}$. Still three, papers more;!?*'. Inevitably, such a confession prompts other illiterate responses like 'LOL' or 'LMFAO'. To avoid linguistic clumsiness, one must employ sufficient self-censorship to evade especially trite sentences or lazy formulations such as 'It is argued that ...' instead of 'Brown argues in his ridiculous essay on page 15 that ...'.

Good writing skills and abstaining from modern media are not sufficient conditions for academic success; it is also necessary that authors possess some expertise in using at least one tool successfully. It must, however, be added that specialization (e.g. employing case studies or running OLS regressions) 
invites aspiring researchers to preach that their hammer can be swung in any analytical environment. Methodological monocultures are the result of limited skilfulness. In purgatory, insufficiently sophisticated academics will be banished to those segregated areas of eternal boredom (like the real-life Balearic Islands or the Algarve, where they are completely among themselves and where they will never meet an advocate of any alternative approach).

Logorrhoea is described succinctly by the Viennese writer Karl Kraus (1925: 60), who famously quipped: 'It is not sufficient to have no thought. One also needs to be able to express it'. ${ }^{7}$ According to Kraus (60), we must have some idea about what we want to write before we start hammering on the machine. This deep insight was most famously coined by a compatriot of Kraus, Oxford philosopher Ludwig Wittgenstein (2003[1922]: 111): 'Whereof one cannot speak, thereof one must be silent'. Obviously, you can try to fill this void with an absolutely unfocussed article, in which you only write in the passive, fill entire pages with one single sentence, remain vague about your goals, and end up with a laundry list of explanatory factors without ever demonstrating what it is that you really want to illuminate. As daring as your attempts may be to tire your readers by producing 'consistently boring scientific literature' (Sand-Jensen, 2007) - we promise eternal hell if you do not attend a decent research design class that prevents you from committing this last of the academic deadly sins.

\section{... AND WHAT CAN BE DONE AGAINST THEM}

Even in the darkest corners of a Wittgensteinian silence, some hope remains that an idea or thought, at some unspecified time, will nevertheless come about. The following seven recommendations are aimed to help you to embark on this journey and to find your role as author in the difficult love-hate triangle you will engage in with your editors and reviewers. The first recommendation is the most trivial one, but most important: you must engage in writing, writing and writing in order to develop a successful publication trajectory. Second, you must aim high for your publications and not accept a personal rejection rate for all your submissions that is below the corrupting 50 per cent level. ${ }^{8}$ In this regard, you should avoid (like the plague) any edited volumes or special issues as the primary outlets for your research. Third, be humble and accept criticism from colleagues, and even from yourself. You will only be able to live up to the concerns of the reviewers when you do not take criticism too personally. In short, you must accept that even someone as great as you - yes, you - can occasionally err. Even if some of the criticism seems to be completely unfair to your genius, do not respond by way of an angry letter to the editor. She might be sympathetic towards your argument, but she also has to protect her reviewers (and, in this way, her own skin) as she picked them as potential experts on your manuscript in the first place. Four, invest most energy into what you consider to be your key contribution. Everything else, such as invitations to write a follow-up piece or to attend conferences in exotic places, constitutes a distraction. Five, organize your time so as to ensure that you are sufficiently lonely every day. For sure, science is also a social enterprise and relies on academic exchange and discussion. Yet to absorb the ideas and suggestions of others and to use them fruitfully for your own innovations, you need to be alone and to stare at the computer screen without hitting (even once!) the 'I like it' button. Six, accept that you cannot be the 
GRÖPAZ, ${ }^{9}$ the 'Greatest Political Scientist of All Times', on all research fronts, simultaneously. An ever-growing number of authors per article is evidence of an increased division of labor and a rising demand for highly skilled specialists. Accept these trends as you can profit from them. (On the other hand, if you have no skills at all, sinning remains your best option. These sinners might take heart in the mistaken claims by some, that sinning is not so bad after all.) Seven, be modest and accept that you cannot be productive $24 \mathrm{~h}$ a day. If you did not have that brilliant idea today and then wasted your time by reading moralizing essays by middle-aged bores like uncle G, remember that you have nevertheless worked hard. Tomorrow is another day for coming up with that path-breaking thought that will boost your personal h-index (Hirsch, 2005) in an unprecedented way!

\section{Notes}

1 Unsurprisingly, the most popular deadly sin in a 1993 MTV survey of entertainers was lust (http:// whitestonejournal.com/index.php/seven-deadly-sins, last consulted 3 January 2011).

2 Merton (1968) referenced the bible to lend Mathew's name to this meritocratic principle. In particular, Matthew 25:29 reads: 'For to all those who have, more will be given, and they will have an abundance; but from those who have nothing, even what they have will be taken away'.

3 Gerber and Malhotra (2008) demonstrate that publication bias is also widespread in top political science journals.

4 Attentive readers will note that this article is no exception to the rule of self-proportion, as this piece includes two self-references (Schneider, 2005, 2007)!

5 The Journal of Tautologies and the Academy of Robust Regression can function as close substitutes.

6 This is my third Empirical Law. The first one states that 'The further away you are geographically in your attempt to theorise the European Union, the more general is your theory.' The second empirical law is similar, and holds that 'The further north you are in Europe, the thicker is your pizza crust'.

7 Kraus correctly classified this insight under the title 'Professional secret'.

8 This recommendation has been attributed to Erich Weede (see Schneider 2005: 258)

9 GRÖPAZ stands for 'Größter Politologe aller Zeiten'.

\section{References}

Bertheau, F. (1888) Göthe und seine Beziehungen zur schweizerischen Baumwoll-Industrie nebst dem Nachweis, dass unter Frau Susanna der Fabrikantenfrau in Wilhelm Meisters Wanderjahren Frau Barbara Schulthess in Zürich zu verstehen ist, Wetzikon, Switzerland: Aktien-Buchdr.

Cherkashin, I., Demidova, S., Imai, S. and Krishna, K. (2009) 'The inside scoop: Acceptance and rejection at the journal of international economics', Journal of International Economics 77: 120132.

Ellison, G. (2002a) 'The slowdown of the economics publishing process', Journal of Political Economy 110(5): 947993.

Ellison, G. (2002b) 'Evolving standards for academic publishing: A q-r theory', Journal of Political Economy 110(5): 9941034.

Fowler, J.H. and Aksnes, D.W. (2007) 'Does self-citation pay?' Scientometrics 72(3): 427437.

Gans, J.S. and Shepherd, G.B. (1994) 'How are the mighty fallen: Rejected classic articles by leading economists', Journal of Economic Perspectives 8(1): 165179.

Gerber, A. and Malhotra, N. (2008) 'Do statistical reporting standards affect what is published? Publication bias in two leading political science journals', Quarterly Journal of Political Science 3(3): 313326.

Hirsch, J. (2005) 'An index to quantify an individual's scientific research output', Proceedings of the National Academy of Sciences 102(46): 569572.

Kraus, K. (1925) 'Die Fackel 697-705', http://corpus1.aac.ac.at/fackel/, accessed 11 May 2011.

Merton, R.K. (1968) 'The Matthew effect in science', Science 57: 6872.

Rabin, M. (1998) 'Psychology and economics', Journal of Economic Literature 36(1): 1146

Sand-Jensen, K. (2007) 'How to write consistently boring scientific literature', Oikos 116: 723727. 
Schneider, G. (2005) 'Erich Weede: A nonconformist conflict researcher', European Political Science 4(3): 256262

Schneider, G. (2007) 'The search for the holy grant: (Mis)allocating money in European political science', European Political Science 6(2): 160168.

Shalvi, S., Baas, M., Handgraaf, M.J.J. and De Dreu, C.K.W. (2010) 'Write when hot Submit when not: Seasonal bias in peer review or acceptance?' Learned Publishing 23(2): 117123.

Starbuck, W. (2005) 'How much better are the most prestigious journals? The statistics of academic publication', Organization Science 16(2): 180200.

Wittgenstein, L. (2003[1922]) Tractatus Logico-Philosophicus, Frankfurt: Suhrkamp.

*This article is based on an invited presentation to the Political Science Faculty at the University of Edinburgh in September 2010 and a subsequent lecture within the Academic Staff Development Programme at the University of Konstanz in November 2011. I would like to thank the audiences as well as two reviewers for their comments and for clearly distinguishing between my serious, and my not so serious, messages. Readers who recognize themselves in my descriptions of the academic deadly sins can rest assured that this text is almost entirely autobiographical. Notwithstanding the author's own frequent failures, they should nevertheless occasionally consider the Latin proverb: 'Qui dormit non peccat' (He who sleeps does not $\sin ^{\prime}$ ).

\section{About the Author}

Gerald Schneider is Professor of Political Science at the University of Konstanz, Germany, where he has held the International Relations Chair since 1997. He is also Executive Editor of European Union Politics. 